\title{
PENGGUNAAN POLY LETTER KEY WORD RADIX CRYPTOGRAPHY DALAM PENGAMANAN PESAN
}

\author{
Eza Budi Perkasa ${ }^{1}$, Elly Yanuarti ${ }^{2}$ \\ Program Studi Teknik Informatika ${ }^{1}$, Program Studi Sistem Informasi ${ }^{2}$ \\ Institut Sains dan Bisnis Atma Luhur ${ }^{1,2}$ \\ ezabudiperkasa@atmaluhur.ac.id ${ }^{1}$, elly@atmaluhur.ac.id ${ }^{2}$
}

\begin{abstract}
Abstrak
Penelitian ini mengenalkan sebuah algoritma kriptografi yang diberi nama Poly Letter Key Word Radix Cryptography yang didasarkan dari basis bilangan (radix). Algoritma kriptografi ini merupakan pengembangan dari algoritma sebelumnya, yaitu (Mono Letter Key) Word Radix Cryptography. Dalam makalah ini, Poly Letter Key Word Radix Cryptography akan diterapkan dalam pengenkripsian pesan. Poly Letter Key Word Radix Cryptography memiliki enam tahapan: Pemindaian kata, enkode, pengubahan basis, penghapusan nol, dekode, dan pengubahan kapitalisasi. Tidak seperti algoritma kriptografi lainnya, panjang dari pesan yang telah diacak dapat tidak sama dan tidak tetap dibandingkan pesan semula.
\end{abstract}

Kata kunci : Kriptografi, Poly Letter Key Word Radix Cryptography, basis bilangan, algoritma

\section{Abstract}

This research introduces a cryptography algorithm called Poly Letter Key Word Radix Cryptography which is based on numerical base (radix). The cryptography algorithm is an improvement of the previous algorithm, namely (Mono Letter Key) Word Radix Cryptography. In this paper, Poly Letter Key Word Radix Cryptography will be applied in encrypting a message. Poly Letter Key Word Radix Cryptography has six steps: Word scanning, encode, base converting, zero removal, decode, and capitalization changing. Unlike other cryptography algorithms, length of the enciphered message can be either unequal or inconstant compared to the original message.

Keywords : Cryptography, Poly Letter Key Word Radix Cryptography, numerical base, algorithm

\section{PENDAHULUAN}

Keamanan dan kerahasiaan data merupakan salah satu dari beberapa aspek penting dari suatu sistem. Dari segi keamanan, umumnya kriptografi merupakan hal utama yang dibahas. Kriptografi merupakan ilmu yang mempelajari cara menjaga data atau pesan tetap aman ketika dikirimkan antarpihak yang berwenang tanpa campur tangan dari pihak lainnya [1]. Tujuan dari kriptografi adalah untuk memberikan layanan keamanan, termasuk keamanan dalam penjagaan kerahasiaan dari pesan. Pesan yang telah dikirim tidak boleh jatuh ke tangan orang yang tidak berhak ataupun tidak berkepentingan [2].

Berdasarkan studi peneliti, teknik-teknik pengamanan pesan dapat dibagi menjadi beberapa kelompok. Kelompok pertama, algoritma kriptografi klasik, merupakan teknik substitusi pesan sederhana dengan mengganti setiap karakter pada pesan dengan karakter lainnya dengan memanfaatkan aritmatika modulo. Jika pesan tersebut merupakan plain text (teks bermakna) yang akan diubah menjadi cipher text (teks acak yang tak bermakna), maka proses tersebut adalah proses enkripsi. Adapun proses sebaliknya (pengubahan cipher text ke plain text) dinamakan dekripsi [3]. Algoritma lainnya yang tergolong dalam kelompok algoritma kriptografi modern menggunakan teknik perhitungan yang lebih kompleks. Contoh dari penerapan algoritma kriptografi ini dapat dilihat pada [4]. Baik algoritma kriptografi klasik ataupun modern, keduanya memiliki kelemahan, yaitu panjang cipher text biasanya sama dengan plain text sehingga dapat diserang menggunakan teknik-teknik dalam kriptanalisis. Oleh karena itu, digunakan teknik lainnya, yaitu fungsi hash. Fungsi tersebut merupakan fungsi satu arah yang berarti pesan yang sudah di-hash tidak dapat dikembalikan seperti semula. Panjang hash ini selalu tetap (tergantung dari algoritma yang digunakan) berapapun panjang pesan semula. Fungsi hash ini pun memiliki kekurangan: Terdapat kemungkinan dua pesan yang berbeda yang memiliki hash yang sama. Akibatnya, pesan yang sampai di tangan penerima bisa jadi berbeda dengan pesan yang dikirimkan sebelumnya.

Penelitian ini akan memperkenalkan sebuah algoritma kriptografi yang bernama Poly Letter Key Word Radix Cryptography (selanjutnya disingkat WRC-PLK). Algoritma tersebut merupakan pengembangan algoritma sebelumnya yang dinamakan (Mono Letter Key) Word Radix Cryptography (selanjutnya disingkat WRC(-MLK)) yang dapat dilihat di [5]. Penjelasan lebih lanjut mengenai WRC-PLK serta perbandingannya dengan WRC(-MLK) dan algoritma kriptografi lain yang merupakan analoginya dibahas pada Bab II. Adapun contoh penerapan algoritma tersebut dapat dilihat pada Bab III.

\section{TENTANG POLY LETTER KEY WORD RADIX CRYPTOGRAPHY}

WRC-PLK adalah algoritma kriptografi yang didasarkan dari basis (radix) bilangan, seperti halnya WRC(-MLK). Perbedaannya, WRC-PLK menggunakan sistem bilangan basis campuran (mixed radix). Dalam sistem bilangan tersebut, sebuah bilangan desimal dapat diubah ke basis lainnya dengan membagi secara berulang-ulang bilangan tersebut dengan nilai basisnya, dimulai dari nilai terkanan hingga pembagian tersebut menghasilkan 0. Angka-angka dari bilangan hasil pengonversian merupakan sisa dari pembagian. Bilangan hasil pengonversian tersebut dibaca dari sisa pembagian terakhir 
ke sisa pembagian pertama. Sebagai contoh, untuk mengonversi 2021 ke basis $(3,4,5)$ dapat dilakukan dengan membagi 2021 dengan 5, 4, dan 3 secara berulang-ulang:

$2021 / 5=404$ sisa 1

$404 / 4=101$ sisa 0

$101 / 3=33$ sisa 2

$33 / 5=6$ sisa 3

$6 / 4=1$ sisa 2

$1 / 3=0$ sisa 1

Dari pembagian berulang tersebut, dapat dilihat bahwa 2021 sama dengan 123201 dalam basis $(3,4,5)$.

Seperti halnya WRC(-MLK), WRC-PLK juga mengguakan tahap pengonversian bilangan dari suatu basis ke basis lainnya dengan sistem numerasi bijektif. Uraian lebih lanjut mengenai sistem numerasi tersebut dapat dilihat di [6]. Alur dari WRC-PLK secara keseluruhan sama dengan WRC(-MLK) dengan sedikit perubahan proses komputasi mengingat key yang digunakan terdiri dari beberapa huruf. Alur tersebut dapat diilustrasikan seperti terlihat pada Gambar 1.

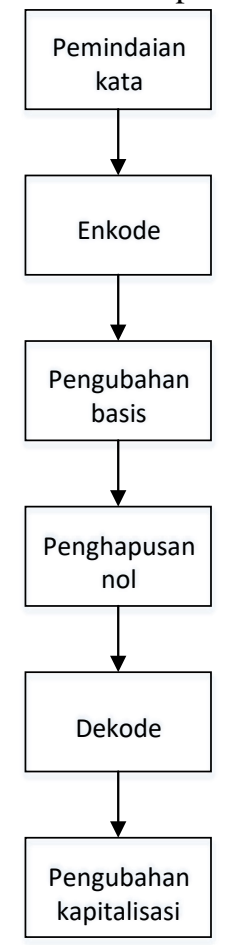

Gambar 1. Alur Word Radix Cryptography [5]

\section{Pemindaian Kata}

Definisi "kata" dalam WRC-PLK sama dengan WRC(-MLK), yaitu sederetan karakter yang diakhiri dengan karakter bukan huruf. Pemindaian kata dilakukan dengan membaca karakter demi karakter hingga akhir kalimat. Jika ditemukan karakter selain huruf, maka kata yang telah dipindai sebelumnya dimasukkan ke dalam variabel. Karakter yang dibaca dan dikonkatenasi bersifat case insensitive sehingga huruf kapital maupun nonkapital dianggap sama.

\section{Enkode}

Tahap enkode adalah tahap untuk mengubah pesan menjadi nilai numerik. Setiap kata memiliki nilai numerik yang unik. Nilai numerik kata untuk plain text adalah $n_{p}$ yang dapat dirumuskan:

$$
n_{p}=\sum_{i=0}^{L-1} n_{C}\left(C_{L-i}\right) \times 26^{i}
$$

dengan $n_{C}$ merupakan nomor urut atau nilai numerik karakter dalam abjad $(\mathrm{A}=1, \mathrm{~B}=2, \mathrm{C}=3, \ldots, \mathrm{Z}=26), L$ merupakan panjang atau jumlah karakter suatu kata, dan $C_{L-i}$ merupakan karakter ke- $(L-i)$ dalam kata. Di lain pihak, nilai numerik kata untuk cipher text, $n_{c}$, memiliki rumus yang hampir sama dengan nilai numerik kata untuk plain text. Perbedaannya terletak pada konstanta 26 yang diganti dengan hasil kali dari $n_{K}$ yang merupakan nilai numerik dari setiap karakter pada key.

$$
n_{c}=\sum_{i=0}^{L-1} n_{C}\left(C_{L-i}\right) \times \prod_{j=1}^{i} n_{K}\left(K_{j}\right)
$$

\section{Pengubahan Basis}

Seperti WRC(-MLK), pengubahan basis dalam WRC-PLK dilakukan dengan pembagian berulang nilai numerik kata dengan $n_{K}$ (dimulai dari karakter key terkanan) untuk proses enkripsi atau 26 untuk proses dekripsi. Dalam 
pemrograman, setiap "digit" dalam hasil pengubahan basis dimasukkan ke sebuah variabel array yang urutan elemennya dibalik.

\section{Penghapusan Nol}

Seperti diuraikan pada [6], sistem numerasi bijektif tidak mengenal angka 0. Untuk menghapus nol dalam bilangan hasil pengubahan basis, angka 0 pada daftar (array) digit diganti dengan $n_{K}$ karakter key yang sesuai pada posisi angka 0 tersebut pada proses enkripsi atau 26 pada proses dekripsi dan angka sebelumnya dikurangi 1 . Jika angka pertama pada daftar digit sama dengan 0 , maka angka tersebut dapat dihapus dari daftar.

\section{Dekode}

Tahap dekode dapat dilakukan dengan syarat daftar digit hasil dari penghapusan nol tidak memiliki elemen tunggal yang nilainya 0 . Dalam tahap ini, setiap angka pada daftar digit diganti menjadi huruf yang nomor urutnya adalah angka bersangkutan $(1=\mathrm{A}, 2=\mathrm{B}, 3=\mathrm{C}, \ldots, 26=\mathrm{Z})$.

\section{Pengubahan Kapitalisasi}

Tahap pengubahan kapitalisasi ini merupakan tahap opsional yang dapat dilakukan jika kata yang telah dienkripsi/dekripsi ingin "diseimbangkan" kapitalisasinya dengan kata semula. Untuk melakukan tahap ini, pertamatama kata hasil dipecah menjadi blok-blok yang masingmasing berisi substring yang kapitalisasinya berselang-seling. Kapitalisasi hanya diubah pada blok substring kapital saja atau nonkapital saja. Pada proses enkripsi, nomor karakter cipher text yang diubah kapitalisasinya adalah $I_{s c}$ sampai $I_{f c}$. Kedua nilai tersebut dapat dirumuskan secara matematis sebagai berikut.

$$
\begin{gathered}
I_{s c}=\left\lfloor\frac{I_{s p}-1}{L_{p}} \times L_{c}\right\rfloor+1 \\
I_{f c}=\left\lfloor\frac{I_{f p}}{L_{p}} \times L_{c}\right\rfloor
\end{gathered}
$$

Sedangkan untuk dekripsi, rumus yang digunakan hampir sama. Perbedaannya, fungsi floor diganti dengan fungsi ceiling dan indeks $c$ diganti dengan $p$ atau sebaliknya.

$$
\begin{gathered}
I_{s p}=\left\lceil\frac{I_{s c}-1}{L_{c}} \times L_{p}\right\rceil+1 \\
I_{f p}=\left\lceil\frac{I_{f c}}{L_{c}} \times L_{p}\right\rceil
\end{gathered}
$$

Pada Persamaan (3) hingga (6), $I_{s p}, I_{f p}, L_{p}$, dan $L_{c}$ berturut-turut adalah nomor karakter awal plain text, nomor karakter akhir plain text, panjang kata plain text, dan panjang kata cipher text. Persamaan (3) dan (5) adalah koreksi dari rumus penentuan nilai $I_{s c}$ dan $I_{s p}$ sebelumnya pada [6] untuk menghindari kapitalisasi yang masih "tidak seimbang" ketika diterapkan pada kata yang telah dienkripsi/dekripsi.

\section{CONTOH PENERAPAN}

Bab ini akan mendemonstrasikan contoh penerapan WRC-PLK dalam pengenkripsian sebuah pesan. Pesan yang

\begin{tabular}{|c|c|c|c|c|c|}
\hline \multicolumn{6}{|c|}{$\begin{array}{c}\text { Plain text } \\
\text { SemInar Nasional peneliTian dan pengAbdian MASyarakat }\end{array}$} \\
\hline $\begin{array}{l}\text { Pemindaian } \\
\text { Kata }\end{array}$ & Enkode & Pengubahan Basis & Penghapusan Nol & Dekode & $\begin{array}{l}\text { Pengubahan } \\
\text { Kapitalisasi }\end{array}$ \\
\hline SemInar & 5934915004 & $\begin{array}{l}2003230122020 \\
01180\end{array}$ & $\begin{array}{l}1913222112111 \\
25111171\end{array}$ & $\begin{array}{l}\text { SACVAAUAA } \\
\text { YAAQA }\end{array}$ & SAcvaaUAayaaqa \\
\hline (spasi) & 0 & 0 & 0 & (spasi) & (spasi) \\
\hline Nasional & 112984390310 & $\begin{array}{l}300502240380 \\
41003120\end{array}$ & $\begin{array}{l}11541223137 \\
14913111\end{array}$ & $\begin{array}{l}\text { AAEDABWAC } \\
\text { GADIACKA }\end{array}$ & AAedabwacgadiacka \\
\hline (spasi) & 0 & 0 & 0 & (spasi) & (spasi) \\
\hline peneliTian & 88030331154780 & $\begin{array}{l}180140414037 \\
03603001140\end{array}$ & $\begin{array}{l}171131413136 \\
135122511131\end{array}$ & $\begin{array}{l}\text { QAACADMA } \\
\text { CFACEABYA } \\
\text { AMA }\end{array}$ & qaacadmacfacEAbyaama \\
\hline (spasi) & 0 & 0 & 0 & (spasi) & (spasi) \\
\hline dan & 2744 & 2100140 & 1915131 & SAEMA & saema \\
\hline (spasi) & 0 & 0 & 0 & (spasi) & (spasi) \\
\hline
\end{tabular}
dienkripsi adalah "SemInar Nasional peneliTian dan pengAbdian MASyarakat" dengan key EZA $\left(n_{K}=(5,26,1)\right)$.

TABEL I

PROSES ENKRIPSI PESAN 
NARATIF(Jurnal Ilmiah Nasional Riset Aplikasi dan Teknik Informatika)

Vol. 03 No. 02 Desember 2021

P-ISSN: 2656-7377 || E-ISSN: 2714-8467

\begin{tabular}{|c|c|c|c|c|c|}
\hline pengAbdian & 88030814811148 & $\begin{array}{l}18014044160119 \\
03250115044140\end{array}$ & $\begin{array}{l}1711131415 \\
111813241 \\
11414131\end{array}$ & $\begin{array}{l}\text { QAACADOA } \\
\text { ARACXAANA } \\
\text { DMA }\end{array}$ & qaacadoaARacxaanadma \\
\hline (spasi) & 0 & 0 & 0 & (spasi) & (spasi) \\
\hline MASyarakat & 70952722311010 & $\begin{array}{l}1403120421010 \\
023022100200\end{array}$ & $\begin{array}{l}1313111141915 \\
251122121915 \\
191\end{array}$ & $\begin{array}{l}\text { MACKADSAE } \\
\text { YABBABSAESA }\end{array}$ & MACKADsaeyabbabsaesa \\
\hline \multicolumn{6}{|c|}{ Cipher text } \\
\hline
\end{tabular}

Berikut diberikan contoh tahap pengenkripsian untuk salah satu kata pada pesan tersebut. Kata yang dimaksud adalah "SemInar"

1. Enkode

Panjang kata "SemInar" adalah 7, sehingga nilai numerik dari kata tersebut adalah

$$
n_{p}=\sum_{i=0}^{6} n_{C}\left(C_{7-i}\right) \times 26^{i}
$$

TABEL II

PROSES ENKODE

\begin{tabular}{|c|c|c|r|}
\hline Karakter & Nilai Karakter & Bobot & Nilai $\times$ Bobot \\
\hline $\mathrm{S}$ & 19 & $26^{6}$ & 5869399744 \\
\hline $\mathrm{e}$ & 5 & $26^{5}$ & 59406880 \\
\hline $\mathrm{m}$ & 13 & $26^{4}$ & 5940688 \\
\hline $\mathrm{I}$ & 9 & $26^{3}$ & 158184 \\
\hline $\mathrm{n}$ & 14 & $26^{2}$ & 9464 \\
\hline $\mathrm{a}$ & 1 & $26^{1}$ & 26 \\
\hline $\mathrm{r}$ & 18 & $26^{0}$ & 18 \\
\hline \multicolumn{3}{|r}{ Nilai numerik kata } & $\mathbf{5 9 3 4 9 1 5 0 0 4}$ \\
\hline
\end{tabular}

2. Pengubahan basis

Basis yang berkesesuaian dengan key EZA adalah $(5,26,1)$. Pembagian berulang untuk nilai kata yang didapat dari Tabel II adalah

$$
\begin{aligned}
& 5934915004 / 1=5934915004 \text { sisa } 0 \\
& 5934915004 / 26=228265961 \text { sisa } 18 \\
& 228265961 / 5=45653192 \text { sisa } 1 \\
& 45653192 / 1=45653192 \text { sisa } 0 \\
& 45653192 / 26=1755892 \text { sisa } 0 \\
& 1755892 / 5=351178 \text { sisa } 2 \\
& 351178 / 1=351178 \text { sisa } 0 \\
& 351178 / 26=13506 \text { sisa } 22 \\
& 13506 / 5=2701 \text { sisa } 1 \\
& 2701 / 1=2701 \text { sisa } 0 \\
& 2701 / 26=\quad 103 \text { sisa } 23 \\
& 103 / 5=20 \text { sisa } 3 \\
& 20 / 1=20 \text { sisa } 0 \\
& 20 / 26=\quad 0 \text { sisa } 20
\end{aligned}
$$

Dari pembagian berulang tersebut, diperoleh nilai kata yang telah diubah basisnya, yaitu 2003230122020 01180 .

3. Penghapusan nol

Nilai kata yang telah diubah basisnya memiliki elemen dengan nilai nol. Oleh karena itu, nilai nol tersebut dapat dihapus sebagai berikut.

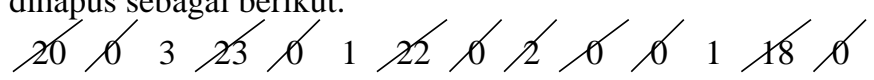




$\begin{array}{llllllllllll}19 & 1 & 22 & 1 & 21 & 1 & 1 & 26 & 1 & 17 & 1 \\ 25 & & & & & \end{array}$

Berdasarkan proses tersebut, diperoleh nilai tanpa elemen nol, yaitu 1913221121112511171

4. Dekode

Dari penghapusan nol sebelumnya, setiap elemen nilai dapat diubah menjadi huruf yang berkesesuaian seperti terlihat pada Tabel III.

TABEL III

PROSES DEKODE

\begin{tabular}{|c|c|c|c|c|c|c|c|c|c|c|c|c|c|c|}
\hline Nilai & 19 & 1 & 3 & 22 & 1 & 1 & 21 & 1 & 1 & 25 & 1 & 1 & 17 & 1 \\
\hline Huruf & S & A & C & V & A & A & U & A & A & Y & A & A & Q & A \\
\hline
\end{tabular}

Berdasarkan huruf yang didapat pada Tabel III, didapat cipher text "SACVAAUAAYAAQA" dengan panjang 14. Cipher text tersebut dapat diubah kapitalisasinya agar "seimbang" dengan plain text semula seperti diuraikan di tahap selanjutnya.

5. Pengubahan kapitalisasi

Plain text semula dapat dikelompokkan menjadi beberapa blok seperti terlihat pada Tabel IV.

TABEL IV

BLOK PLAIN TEXT

\begin{tabular}{|c|c|c|c|c|c|c|c|}
\hline Nomor & 1 & 2 & 3 & 4 & 5 & 6 & 7 \\
\hline Huruf & S & e & m & I & $\mathrm{n}$ & $\mathrm{a}$ & $\mathrm{r}$ \\
\hline Blok & I & \multicolumn{3}{|c|}{ II } & III & \multicolumn{5}{|c|}{ IV } \\
\hline
\end{tabular}

Berdasarkan pembagian blok plain text tersebut, dapat ditentukan batasan-batasan blok cipher text sebagai berikut.

a. Untuk blok I, $I_{s p}=1$ dan $I_{f p}=1$ sehingga $I_{s c}=\left\lfloor\frac{1-1}{7} \times 14\right\rfloor+1=\lfloor 0\rfloor+1=0+1=1$ dan $I_{f c}=\left\lfloor\frac{1}{7} \times 14\right\rfloor=$ $\lfloor 2\rfloor=2$

b. Untuk blok II, $I_{s p}=2$ dan $I_{f p}=3$ sehingga $I_{s c}=\left\lfloor\frac{2-1}{7} \times 14\right\rfloor+1=\lfloor 2\rfloor+1=2+1=3$ dan $I_{f c}=$ $\left\lfloor\frac{3}{7} \times 14\right\rfloor=\lfloor 6\rfloor=6$

c. Untuk blok III, $I_{s p}=4$ dan $I_{f p}=4$ sehingga $I_{s c}=\left\lfloor\frac{4-1}{7} \times 14\right\rfloor+1=\lfloor 6\rfloor+1=6+1=7$ dan $I_{f c}=$ $\left\lfloor\frac{4}{7} \times 14\right\rfloor=\lfloor 8\rfloor=8$

d. Untuk blok IV, $I_{s p}=5$ dan $I_{f p}=7$ sehingga $I_{s c}=\left\lfloor\frac{5-1}{7} \times 14\right\rfloor+1=\lfloor 8\rfloor+1=8+1=9$ dan $I_{f c}=$ $\left\lfloor\frac{7}{7} \times 14\right\rfloor=\lfloor 14\rfloor=14$

TABEL V

BLOK CIPHER TEXT

\begin{tabular}{|c|c|c|c|c|c|c|c|c|c|c|c|c|c|c|}
\hline Nomor & 1 & 2 & 3 & 4 & 5 & 6 & 7 & 8 & 9 & 10 & 11 & 12 & 13 & 14 \\
\hline Blok & \multicolumn{2}{|c|}{ I } & \multicolumn{4}{|c|}{ II } & \multicolumn{2}{|c|}{ III } & \multicolumn{6}{|c|}{ IV } \\
\hline Huruf & $\mathrm{S}$ & A & $\mathrm{c}$ & $\mathrm{V}$ & $\mathrm{a}$ & $a$ & $\mathrm{U}$ & $\mathrm{A}$ & $\mathrm{a}$ & $\mathrm{y}$ & $\mathrm{a}$ & $\mathrm{a}$ & $\mathrm{q}$ & $\mathrm{a}$ \\
\hline
\end{tabular}

Dari pembagian blok pada Tabel V, diperoleh cipher text yang kapitalisasinya sudah "seimbang" dengan plain text semula, yaitu "SAcvaaUAayaaqa".

\section{KESIMPULAN}

Makalah ini memperkenalkan sebuah algoritma kriptografi yang diberi nama Poly Letter Key Word Radix Cryptography. Pada penelitian ini, algoritma tersebut diterapkan dalam pengenkripsian pesan. Algoritma kriptografi tersebut merupakan pengembangan dari algoritma (Mono Letter Key) Word Radix Cryptography. Penelitian selanjutnya dapat menggunakan pendekatan yang berbeda, misalnya dengan menggunakan nilai ASCII untuk setiap karakter (termasuk karakter khusus).

\section{REFERENSI}

[1] E. Handayani, W. L. Pratitis, A. Nur, S. A. Mashuri, dan B. Nugroho, "Perancangan Aplikasi Kriptografi Berbasis Web Dengan Algoritma Double Caesar Cipher Menggunakan Tabel ASCII," dalam Seminar Nasional Teknologi Informasi dan Multimedia 2017, 2017, hal. 241-246.

[2] C. A. Sari, E. H. Rachmawanto, D. W. Utomo, dan R. R. Sani, "Penyembunyian Data Untuk Seluruh Ekstensi File Menggunakan Kriptografi Vernam Cipher dan Bit Shiffting," Journal of Applied Intelligent System, vol. 1, hal. 179-190, Okt. 2016.

[3] R. K. Hondro. "Aplikasi Enkripsi dan Dekripsi SMS Dengan Algoritma Zig Zag Cipher Pada Mobile Phone Berbasis Android," Pelita Informatika Budi Darma, vol. X, Jul. 2015. 
NARATIF(Jurnal Ilmiah Nasional Riset Aplikasi dan Teknik Informatika)

Vol. 03 No. 02 Desember 2021

P-ISSN: 2656-7377 || E-ISSN: 2714-8467

[4] K. Aryasa dan Y. T. Paulus, "Implementasi Secure Hash Algorithm-1 Untuk Pengamanan Data Dalam Library Pada Pemrograman Java," Citec Journal, vol. 1, hal. 57-66, Nov. 2013.

[5] E. B. Perkasa, R. Sulaiman, D. Y. Sylfania, dan F. P. Juniawan, "Word Radix Cryptography: Pengenalan dan Contoh Penggunaannya," dalam Seminar Nasional Telekomunikasi dan Informatika, 2018, hal. 45-49.

[6] H. H. Hansen, C. Kupke, J. Rutten, dan J. Winter, “A Final Coalgebra for $k$-regular Sequences," dalam Horizons of the Mind. A Tribute to Prakash Panangaden, 2014, hal. 363-383. 